\title{
Salivary Nitrite in Patients with Type 2 Diabetes Mellitus: Role of Diabetic Pharmacotherapy
}

\author{
Hayder M Alkuraishy ${ }^{1 *}$, Ali I Al-Gareeb1, Marta C Monteiro ${ }^{2}$, Salah A Al-windy ${ }^{3}$ and Huda Jaber ${ }^{4}$ \\ ${ }^{1}$ Department of Pharmacology, Toxicology and Medicine College of Medicine Almustansiriya University, Iraq \\ ${ }^{2}$ Department of Pharmaceutical Science Post-Graduation Program, Neuroscience and Cell Biology Post-graduate Program Health Science Institute, \\ Iraq
}

${ }^{3}$ Department of Biology and Biochemistry, College of Sciences Baghdad University, Iraq

${ }^{4}$ Department of biochemistry, College of Pharmacy, Iraq

Submission: January 6, 2017; Published: February 06, 2017

*Corresponding author: Hayder M Alkuraishy, Department of Pharmacology, Toxicology and Medicine College of Medicine Almustansiriya University, Iraq, Tel: +96407906230487; Email: Hayderm36@Yahoo.Com

\begin{abstract}
Salivary nitrite is derived from salivary nitrate that obtained from ingested nitrate since $25 \%$ of nitrate is secreted through saliva thus; salivary nitrate is 10-20 times higher than plasma nitrate. Nitrate-nitric-NO pathway plays a role in prevention of insulin resistance and progression of diabetes mellitus. Because of salivary nitrite is also generated from NO metabolism therefore, salivary nitrite may reflect the endogenous NO production and endothelial function in various diseases thus; the aim of present study was evaluation of salivary nitrite in controlled and complicated T2DM regarding the current diabetic pharmacotherapy. In this study a total number of 50 patients with T2DM were selected randomly compared with 27 healthy subjects. $10 \mathrm{ml}$ of venous blood from all patients and healthy subjects after an overnight fasting was drawn, lipid profile, fasting blood glucose, plasma nitrate, plasma nitrite, nitric oxide NO and salivary nitrite were determined in patients with T2DM regarding specific diabetic pharmacotherapy and complications compared to healthy control. Salivary nitrite was high in patient with complications $\mathrm{p}=0.04$ compared with control and near normal in diabetic patient without complications. Metformin increases salivary nitrite more than glimepiride but combination of metformin plus glimepiride produced significant amelioration in salivary nitrite levels.
\end{abstract}

Conclusion: Salivary nitrite levels were high in complicated T2DM and low in controlled T2DM compared to the control. Metformin increases salivary nitrite levels whereas glimepiride alone or in combination with metformin reduce salivary nitrite levels in T2DM patients.

Keywords: Salivary nitrite; Metformin; glimepiride; T2DM

Abbreviations: T2DM: Type 2 Diabetes Mellitus; MIP: Macrophage Inflammatory Protein; GLUT4: Glucose Transporter 4; VEGF: Vascular Endothelial Growth Factor

\section{Introduction}

Type 2 diabetes mellitus (T2DM) is an endocrine and metabolic disorder characterized by hyperglycemia and inflammatory changes that cause systemic complications due to nitric oxide disorders that cause endothelial dysfunction [1]. Inorganic nitrite and nitrate are found in vegetable food and drinking water, this nitrate/nitrite compounds are responsible for restoring of nitric oxide NO which play an important role in prevention of insulin resistance and development of T2DM [2]. Previously, nitrate/nitrite compounds were reported to be a risk factor in development of T2DM [3]. Salivary nitrite is derived from salivary nitrate that obtained from ingested nitrate since $25 \%$ of nitrate is secreted through saliva thus; salivary nitrate is 10-20 times higher than plasma nitrate [4]. Moreover, nitrite is responsible for synthesis of $\mathrm{NO}$ via independent-nitric oxide synthase pathway that called nitrate-nitric-NO pathway, so diet deficient nitrate lead to cardiac and hepatic damage due to ischemic-reperfusion injury [5].

Nitrate-nitric-NO pathway plays a role in prevention of insulin resistance and progression of diabetes mellitus since; NO increase insulin sensitivity and secretion at post-receptor signaling also, NO improves insulin action through reduction of proinflammatory cytokines that down-regulate glucosetransporter 4(GLUT4) thus; NO inhibits mitochondrial reactive oxygen species production which are implicated in the induction 
of insulin resistance [6]. Indeed, the impact of T2DM on NO production is revealed through different mechanisms which are:

i. Longstanding hyperglycemia leads to induction of oxidative stress and buildup of advance glycation end products that inhibit nitrate-nitric-NO pathway [7].

ii. Chronic hyperglycemia induces production of dimethylarginine which inhibit nitrate-nitric-NO pathway [8].

iii. Stimulation of arginase activity that decrease the availability of arginine for NO synthesis [9].

iv. Inhibition of NO synthesis due to insulin impairment [10].

Regarding diabetic pharmacotherapy, metformin is a biguanide approved for management of T2DM, it possess significant anti-inflammatory and anti-oxidant effects that reducing the cardio-metabolic complications [11], additionally, metformin improves endothelial function through regulation of endothelial NO and attenuating the inflammatory-induced vascular endothelial function [12]. Alternatively, glimepiride which is a long acting secretagogus sulfonylurea acts through augmentation of peripheral insulin sensitivity and stimulation of insulin secretion from pancreatic $\beta$-cells [13]. Generally, sulfonylurea reduced NO production [14] but it is little known about glimepiride effect on nitrate-nitric-NO pathway. Because of salivary nitrite is also generated from NO metabolism therefore, salivary nitrite may reflect the endogenous NO production and endothelial function in various diseases thus; the aim of present study was evaluation of salivary nitrite in controlled and complicated T2DM regarding the current diabetic pharmacotherapy.

\section{Materials and Methods}

In this observational study a total number of 50 patients with T2DM were selected randomly from Iraqi endocrinology center, compared with 27 healthy subjects. Moreover, T2DM patients were subdivided into two groups: group 1 involved 22(44\%) patients with diabetic complications; group 2 involved 28 (56) \% patients without complications. All patients and control subjects gave a verbal consent for their participation in this study. This study was approved by scientific jury and ethical committee. A full history was been undertaken for all patients regarding disease duration, current pharmacotherapy, dietary schedule (avoiding high nitrate food for 12 prior to the test) and associated diseases, and any patient with end stage or severe complications were excluded .

\section{Biochemical measurements}

$10 \mathrm{ml}$ of venous blood from all patients and healthy subjects after an overnight fasting was drawn, after centrifugation the sera were stored at $-20^{\circ} \mathrm{C}$ for analysis. Lipid profile was estimated by specific kit method according to the kit instructions; VLDL and LDL were estimated according to specific formula [15]. Fasting blood glucose was determined by fasting capillary method [16]. Plasma nitrate, plasma nitrite in $\mu \mathrm{M}$ and nitric oxide NO $\mu \mathrm{mol} / \mathrm{L}$ was determined according to the specific method [17]. Direct strip method was used for estimation of salivary nitrite ( $\mu \mathrm{mol} / \mathrm{L})$ according to the specific method [18]. the samples are taken at $8.00 \mathrm{am}$ and immediately used to avoid the diurnal variations.

\section{Statistical analysis}

Data of the present study were expressed as mean \pm $\mathrm{SD}$, percentages and numbers. Unpaired t test was used for determination the significance of differences compared with control, whereas ANOVA test was used to detects the significance of differences among the diabetic patients and control subjects, regarding $\mathrm{p}$ is significant when it $<0.05$. SPSS version 21 was used for analysis the data of the present study.

\section{Results}

Table1: Characteristics of the present study.

\begin{tabular}{|c|c|}
\hline Variables & The Characteristics \\
\hline Number & 77 \\
\hline Diabetic patients & $50(64.93)$ \\
\hline Control & $27(35.06)$ \\
\hline Gender M:F ratio & $\begin{array}{c}28 \text { male (71.42), } 22 \text { female } \\
(28.57)\end{array}$ \\
\hline Age (years) & $49.66 \pm 11.31$ \\
\hline Duration of type 2DM (years) & $6.33 \pm 2.59$ \\
\hline $\begin{array}{c}\text { Patients with complicated type } \\
\text { 2DM }\end{array}$ & $22(44)$ \\
\hline $\begin{array}{l}\text { Patients with non-complicated } \\
\text { type 2DM }\end{array}$ & $28(56)$ \\
\hline \multicolumn{2}{|c|}{ Associated Diseases } \\
\hline Hypertension & $16(32)$ \\
\hline Ischemic heart diseases & $14(28)$ \\
\hline Dyslipidemia & $20(40)$ \\
\hline Asthma & $2(4)$ \\
\hline \multicolumn{2}{|c|}{ Diabetic Pharmacotherapy } \\
\hline Metformin & $12(24)$ \\
\hline Sulfonylurea & $11(22)$ \\
\hline Sitagliptin & $3(6)$ \\
\hline Metformin + Sulfonylurea & $14(28)$ \\
\hline Metformin + Sitagliptin & $1(2)$ \\
\hline Insulin & $10(20)$ \\
\hline \multicolumn{2}{|c|}{ Others } \\
\hline Statins & $20(40)$ \\
\hline CCB & $11(22)$ \\
\hline ACEI & $5(10)$ \\
\hline Anti platelets & $39(78)$ \\
\hline Theophylline & $2(4)$ \\
\hline Smoking & $41(82)$ \\
\hline
\end{tabular}

Data are expressed as Mean \pm SD, $\mathrm{n}(\%)$; CCB: calcium channel blockers; ACEl: angiotensin converting enzyme inhibitors. 


\section{Global Journal of Pharmacy \& Pharmaceutical Sciences}

A total number of 50 patients compared with 27 normal healthy subjects were included in this study. The duration of T2DM was $6.33 \pm 2.59$ years, $44 \%$ of diabetic patients $(n=22)$ presented with complications whereas; $56 \%$ of diabetic patients $(n=28)$ not associated with diabetic complications. The associated diseases with T2DM in this study were hypertension16 (32\%), ischemic heart diseases 14(28\%), dyslipidemia20 (40\%) and asthma 2(4\%). Most of diabetic patients were on current therapy of metformin $24 \%$ and metformin plus sulfonylurea $28 \%$ also, $82 \%$ of diabetic patients $(n=41)$ were smokers. Other treatments that are received by the diabetic patients were calcium channel blockers, angiotensin converting enzyme inhibitors, statins, antiplatelets and theophylline, Table 1 showed the characteristics of enrolled patients. In T2DM patients without complications there was well-controlled fasting blood glucose, HbA1c p>0.05 as compared with control but in those patients there is dyslipidemic state $\mathrm{p}<0.05$ compared with control without significance of differences regarding plasma nitrate, plasma nitrite, salivary nitrite and endogenous NO levels p $>0.05$ compared with control.

Table 2: Differences in the salivary nitrite levels and plasma nitrate-nitrite-NO pathway in T2DM patients with and without complications compared with control.

\begin{tabular}{|c|c|c|c|c|}
\hline Variables & Control (N=27) & $\begin{array}{c}\text { Diabetic without } \\
\text { Complications (N=28) }\end{array}$ & $\begin{array}{c}\text { Diabetic with } \\
\text { Complications (N=22) }\end{array}$ & ANOVA \\
\hline FBG (mg/Dl) & $91.22 \pm 13.23$ & $125.68 \pm 12.63$ & $166.89 \pm 18.48^{*}$ & $<0.01$ \\
\hline HbA1c (\%) & $4.6 \pm 1.33$ & $6.55 \pm 2.58^{*}$ & $9.82 \pm 3.52^{*}$ & $<0.01$ \\
\hline TC(mg/Dl) & $110.83 \pm 11.62$ & $144.64 \pm 14.82^{*}$ & $215.68 \pm 19.22^{*}$ & $<0.01$ \\
\hline TG(mg/Dl) & $133.93 \pm 16.69$ & $158.61 \pm 17.22^{*}$ & $299.61 \pm 18.29^{*}$ & $<0.01$ \\
\hline HDL(mg/Dl) & $54.73 \pm 9.41$ & $46.97 \pm 10.61^{*}$ & $36.91 \pm 6.11^{*}$ & $<0.01$ \\
\hline VLDL(mg/Dl) & $29.79 \pm 8.41$ & $31.72 \pm 8.69$ & $59.92 \pm 8.52^{*}$ & $<0.01$ \\
\hline LDL(mg/Dl) & $29.31 \pm 6.39$ & $65.94 \pm 9.55^{*}$ & $118.84 \pm 14.69 *$ & $<0.01$ \\
\hline Plasma nitrate (Mm) & $25.13 \pm 6.56$ & $23.22 \pm 6.33$ & $21.82 \pm 6.82$ & 0.212 \\
\hline Plasma nitrite(Mm) & $3.29 \pm 1.44$ & $2.77 \pm 1.39$ & $4.27 \pm 1.33^{* *}$ & 0.001 \\
\hline Salivary nitrite ( $\mu \mathrm{mol} / \mathrm{L})$ & $55.63 \pm 11.85$ & $56.81 \pm 10.49$ & $61.99 \pm 9.31^{* *}$ & 0.37 \\
\hline NO( $\mu \mathrm{mol} / \mathrm{L})$ & $88.51 \pm 18.69$ & $79.53 \pm 18.35$ & $99.99 \pm 21.71^{* *}$ & 0.015 \\
\hline
\end{tabular}

Unpaired $t$ test: ${ }^{*}<0.01,{ }^{* *} p<0.05$ as compared with control, FBG: fasting blood glucose; HbA1c: glycated hemoglobin; TC: total cholesterol; TG: triglyceride; HDL: high density lipoprotein; VLDL: very low density lipoprotein; LDL: low density lipoprotein; NO: nitric oxide.

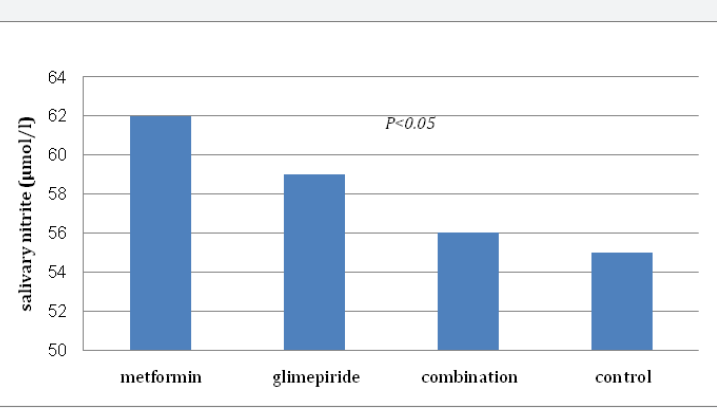

Figure 1: Effects of diabetic pharmacotherapy on salivary nitrite levels.

In T2DM patients with complications there were significant hyperglycemia, dyslipidemia, elevated plasma nitrite, reduced plasma nitrate, elevated salivary nitrite and elevated endogenous NO levels therefore; salivary nitrite was high in patient with complications $\mathrm{p}=0.04$ compared with control and near normal in diabetic patient without complications (Table 2). Regarding the diabetic pharmacotherapy, metformin increases salivary nitrite more than glimepiride but combination of metformin plus glimepiride produced significant amelioration in salivary nitrite levels. In the present study most of diabetic patients without complications were on combination therapy whereas most of diabetic patients with complications were on monotherapy of either metformin or glimepiride (Figure 1). Regarding the significance value of salivary nitrite test in this study it was highly sensitive with moderate specificity with comparable positive and negative predictive value (Table 3).

Table 3: Sensitivity and specificity of salivary nitrite test in patients with type 2 DM.

\begin{tabular}{|c|c|}
\hline Salivary Nitrite & $\begin{array}{c}\text { Value + 95\% CI (Upper-Lower } \\
\text { Limits) }\end{array}$ \\
\hline Sensitivity & $95.24 \%+(83.84-99.42)$ \\
\hline Specificity & $62.50 \%+(24.49-91.48)$ \\
\hline Positive likelihood ratio & $2.54+(1.04-6.23)$ \\
\hline Negative likelihood ratio & $0.08+(0.02-0.33)$ \\
\hline Positive predictive value & $93.02 \%+(80.94-98.54)$ \\
\hline Negative predictive value & $71.43 \%+(29.04-96.33)$ \\
\hline
\end{tabular}

\section{Discussion}

The present study illustrated that salivary nitrite was low in patients with controlled T2DM and high in T2DM patients with complications compared with normal healthy control subjects, these findings were corresponded with Francesconi, et al. [19] study that showed changes in nitrate and nitrate levels may reflect the endogenous NO production and metabolic alterations induced by hyperglycemia [19] Moreover, elevation and reduction in nitrate and nitrite levels were revealed in 


\section{Global Journal of Pharmacy \& Pharmaceutical Sciences}

T2DM compared with control due to metabolic disturbances and diabetic-induced complications such as nephropathy that causing significant elevation in nitrate/nitrite levels due to activation of inducible NO synthase enzyme, inflammatory changes and insulin resistance [20].

Indeed, changes in salivary nitrite in the patients with T2DM may be due to diabetic-induced alterations in the salivary flow and compositions [21]. Results of present study as well showed significant changes in NO serum levels, high in complicated and low in non-complicated T2DM since; increased nitrate/ nitrite plasma levels with increased NO production could be a compensatory mechanism against insulin resistance and diabetic-induced oxidative stress [22] thus; augmented nitratenitrite-NO pathway was reflected via increasing in the salivary nitrite levels whereas; well controlled diabetic patients exhibited low nitrate/nitrite levels [23].

Moreover, the present study showed that diabetic-induced dyslipiemia was more observed in patients with complicated T2DM, this dyslipidemia may affect the endothelial function and NO production [24]. Therefore, augmentation in the nitrite/ nitrate plasma levels in complicated T2DM could have a beneficial effect in prevention the progression of diabetic complications since; plasma nitrite/nitrate has interesting antioxidant and anti-inflammatory actions that ameliorate endogenous catalase and glutathione activity as well as improves the level of proinflammatory cytokines [25].

On the other hand, $81 \%$ of recruited patients were smokers that may affect the nitrite/nitrate/NO pathway as illustrated by Retterstol, et al. [26] study that showed low level of nitrate and nitrite levels in smokers healthy subjects [26] but in our study high level of nitrite/nitrate/NO pathway was showed in complicated T2DM smoker patients since; chronic nicotine smoking leads to significant endothelial dysfunction [27]. Regarding T2DM pharmacotherapy in the present study, most of patients were treated by either metformin and/or glimepiride these agents may also affect nitrite/nitrate/NO pathway seeing as; metformin improves endothelial function in T2DM patients that reflected by increase in the NO levels with subsequent augmentation in nitrite/nitrate plasma levels that excreted though salivary rout as salivary nitrite $[28,29]$ thus; metformin improves NO through AMP-activated protein kinase activation that responsible for up regulation of eNOS and then NO production and inhibition of Rho kinas which implicated in the development of endothelial dysfunction and reduction of endothelial NO production [30]. Indeed, glimepiride have potent anti-inflammatory and antioxidant activities through reduction of vascular endothelial growth factor (VEGF) and macrophage inflammatory protein (MIP) that contributes into prevention of diabetic-induced endothelial dysfunction and the alteration in the NO production [31] Furthermore, salivary nitrite in the present study was highly sensitive but less specific with high positive predicative value since; all samples were taken at morning and immediately used for analysis in view of the fact that salivary nitrite levels are highs affected by sample time, storage and analysis time [32,33].

\section{Conclusion}

Salivary nitrite levels were high in complicated T2DM and low in controlled T2DM compared to the control. Metformin increases salivary nitrite levels whereas glimepiride alone or in combination with metformin reduce salivary nitrite levels in T2DM patients.

\section{References}

1. Ozanne SE, Rahmoune H, Guest PC (2017) Multiplex Biomarker Approaches in Type 2 Diabetes Mellitus Research. Methods Mol Biol 1546: 37-55.

2. Kobayashi J, Ohtake K, Uchida H (2015) NO-Rich Diet for LifestyleRelated Diseases. Nutrients 7(6): 4911-4937.

3. Ghasemi A, Zahediasl S, Azizi F (2012) High serum nitric oxide metabolites and incident metabolic syndrome. Scand J Clin Lab Invest 72(7): 523-530.

4. Qu XM, Wu ZF, Pang BX, Jin LY, Qin L, et al. (2016) From Nitrate to Nitric Oxide: The Role of Salivary Glands and Oral Bacteria. J Dent Res 95(13): 1452-1456

5. Antonio Gonzalez, Embriette Hyde, Naseer Sangwan, Jack A Gilbert, Erik Viirre, et al. (2016) Migraines Are Correlated with Higher Levels of Nitrate-, Nitrite-, and Nitric Oxide-Reducing Oral Microbes in the American Gut Project Cohort. MSystems 1(5) pp: e00105-00116.

6. Peleli M, Zollbrecht C, Montenegro MF, Hezel M, Zhong J, et al. (2016) Enhanced XOR activity in eNOS-deficient mice: Effects on the nitratenitrite-NO pathway and ROS homeostasis. Free Radic Biol Med 99: 472-484.

7. Yamazaki KG, Gonzalez E, Zambon AC (2012) Crosstalk between the renin-angiotensin system and the advance glycation end product axis in the heart: role of the cardiac fibroblast. J Cardiovasc Transl Res 5(6): 805-813.

8. Yan LJ (2014) Pathogenesis of chronic hyperglycemia: from reductive stress to oxidative stress. J Diabetes Res 2014: 137919.

9. Huynh NN, Chin-Dusting J (2006) Amino acids, arginase and nitric oxide in vascular health. Clin Exp Pharmacol Physiol 33(1-2): 1-8.

10. Brinkmann C, Schulte-Körne B, Grau M, Obels S, Kemmerling R, et al. (2016) Effects of Endurance Training on the Skeletal Muscle Nitric Oxide Metabolism in Insulin-Independent Type 2 Diabetic Men-A Pilot Study. Metab Syndr Relat Disord 26.

11. Alkuraishy HM, Al-Gareeb AI (2015) New Insights into the Role of Metformin Effects on Serum Omentin-1 Levels in Acute Myocardial Infarction: Cross-Sectional Study. Emerg Med Int 2015: 283021.

12. Ahmed FW, Rider R, Glanville M, Narayanan K, Razvi S, et al. (2016) Metformin improves circulating endothelial cells and endothelial progenitor cells in type 1 diabetes: MERIT study. Cardiovasc Diabetol 15(1): 116.

13. Perl S, Cook W, Wei C, Ohman P, Hirshberg B (2016) Effects of Glimepiride versus Saxagliptin on $\beta$-Cell Function and Hypoglycemia: A Post Hoc Analysis in Older Patients with Type 2 Diabetes Inadequately Controlled with Metformin. Clin Ther 38(12): 2578-2588.

14. O'Brien A, Stidwill RP, Clapp LH, Singer M (2009) Variable effects of inhibiting iNOS and closing the vascular ATP-sensitive potassium channel (via its pore-forming and sulfonylurea receptor subunits) in endotoxic shock. Shock 31(5): 535-541. 
15. Chaen H, Kinchiku S, Miyata M, Kajiya S, Uenomachi H, et al. (2016) Validity of a Novel Method for Estimation of Low-Density Lipoprotein Cholesterol Levels in Diabetic Patients. J Atheroscler Thromb 23(12): 1355-1364

16. Park HI, Lee SS, Son JW, Kwon HS, Kim SR, et al. (2016) Analytical Performance Evaluation of Infopia Element ${ }^{\mathrm{TM}}$ auto-coding Blood Glucose Monitoring System for Self-Monitoring of Blood Glucose. J Clin Lab Anal 30(6): 849-858.

17. Li H, Meininger CJ, Wu G (2000) Rapid determination of nitrite by reversed-phase high-performance liquid chromatography with fluorescence detection. J Chromatogr B Biomed Sci Appl 746(2): 199207.

18. Francis CA, Hector MP, Proctor GB (2001) Levels of pre-kallikrein in resting and stimulated human parotid and submandibular saliva. Eur J Oral Sci 109(5): 365-368

19. Francesconi F, Mingardi R, deKreutzenberg S, Avogaro A (2001) Effect of metabolic control on nitrite and nitrate metabolism in type 2 diabetic patients. Clin Exp Pharmacol Physiol 28(7): 518-521.

20. Tessari P, Cecchet D, Cosma A, Vettore M, Coracina A, et al. (2010) Nitric oxide synthesis is reduced in subjects with type 2 diabetes and nephropathy. Diabetes 59(9): 2152-2159.

21. Lasisi TJ, Fasanmade AA (2012) Salivary flow and composition in diabetic and non-diabetic subjects. Niger J Physiol Sci 27(1): 79-82.

22. Bahadoran Z, Ghasemi A, Mirmiran P, Azizi F, Hadaegh F (2015) Beneficial effects of inorganic nitrate/nitrite in type 2 diabetes and its complications. Nutr Metab 12: 16.

23. Fujita K, Wada K, Nozaki Y, Yoneda M, Endo H, et al. (2011) Serum nitric oxide metabolite as a biomarker of visceral fat accumulation: clinical significance of measurement for nitrate/nitrite. Med Sci Monit 17(3): 123-131.

24. Kumar S, Trivedi A, Verma N, Panwar A, Kumar P (2016) Evaluation of the Serum Levels of Nitric Oxide among Diabetic Patients and its Correlation with Lipid Profile as well as Oxidative Stress in North Indian Setting. J Clin Diagn Res 10(5): 44-47.
25. Carlström M, Persson AE, Larsson E, Hezel M, Scheffer PG, et al. (2011) Dietary nitrate attenuates oxidative stress, prevents cardiac and renal injuries, and reduces blood pressure in salt-induced hypertension. Cardiovasc Res 89(3): 574-585.

26. Retterstol L, Lyberg T, Aspelin T, Berg K (2006) A twin study of nitric oxide levels measured by serum nitrite/nitrate. Twin Res Hum Genet 9(2): 210-214.

27. Neunteufl T, Heher S, Kostner K, Mitulovic G, Lehr S, et al. (2002) Contribution of nicotine to acute endothelial dysfunction in long-term smokers. J Am Coll Cardiol 39(2): 251-256.

28. An H, Wei R, Ke J, Yang J, Liu Y, et al. (2016) Metformin attenuates fluctuating glucose-induced endothelial dysfunction through enhancing GTPCH1-mediated eNOS recoupling and inhibiting NADPH oxidase. J Diabetes Complications 30(6): 1017-1024.

29. Liu Y, Huang C, Ceng C, Zhan H, Zheng D, et al. (2014) Metformin enhances nitric oxide production and diminishes Rho kinase activity in rats with hyperlipidemia. Lipids Health Dis 13: 115.

30. Hirose A, Tanikawa T, Mori H, Okada Y, Tanaka Y (2010) Advanced glycation end products increase endothelial permeability through the RAGE/Rho signaling pathway. FEBS Lett 584(1): 61-66.

31. Hayder M Al-Kuraishy, Ali I Al-Gareeb (2016) Erectile Dysfunction and Low Sex Drive in Men with Type 2 DM: The Potential Role of Diabetic Pharmacotherapy. Journal of clinical and diagnostic research 10(12): 21-26.

32. Sánchez GA, Miozza VA, Delgado A, Busch L (2014) Total salivary nitrates and nitrites in oral health and periodontal disease. Nitric Oxide 36: 31-35.

33. Ren H, Qiu H, Liang X, Wang X, Jiang S (2013) Determination of inorganic anions in saliva by electroosmotic flow controlled counterflow isotachophoretic stacking under field-amplified sample injection. J Chromatogr B Analyt Technol Biomed Life Sci 935: 75-79.

Your next submission with Juniper Publishers will reach you the below assets

- Quality Editorial service

- Swift Peer Review

- Reprints availability

- E-prints Service

- Manuscript Podcast for convenient understanding

- Global attainment for your research

- Manuscript accessibility in different formats

( Pdf, E-pub, Full Text, Audio)

- Unceasing customer service

Track the below URL for one-step submission

https://juniperpublishers.com/online-submission.php 